\title{
Technical Efficiency of the Malaysian Wooden Furniture Industry: A Stochastic Frontier Production Approach
}

\author{
Alias Radam \\ Faculty of Economics and Management \\ Universiti Putra Malaysia, 43400 UPM Serdang \\ E-mail: alias@econ.upm.edu.my \\ Mohd Rusli Yacob (Corresponding Author) \\ Faculty of Economics and Management \\ Universiti Putra Malaysia, 43400 UPM Serdang \\ E-mail: mroy@econ.upm.edu.my \\ Huda Farhana Mohd Muslim \\ Forest Research Institute Malaysia, 52109 Kepong, Selangor \\ E-mail: hudafarhana@frim.gov.my
}

\begin{abstract}
Wood furniture industry is an important component in our manufacturing sector for it significantly contributes to the industrialization of Malaysia's economy. Evaluating wood furniture industry's level of efficiency is important to assist and provide a relative direction to small and medium firms on their business. The objective of this research is to examine the efficiency of wooden furniture industry by determining the technical efficiency using stochastic frontier production model. Results show that firm output is 54 per cent less than the maximal output which can be achieved from the existing inputs. The technical inefficiency on individual firm varies from 1.63 to 94.69 per cent and so does the potential to increase firm output from the existing inputs. This evidence suggests that many firms still operate below the efficiency level, confirming the conventional view that labor-intensive firms are most likely inefficient.
\end{abstract}

Keywords: Technical efficiency, Stochastic frontier model, Wooden furniture industry

\section{Introduction}

The furniture sub-sector is largely export-oriented, with more than 90 per cent of its production exported. In 2005, wooden furniture contributed 27.8 per cent to the total export earnings in the industry exceeding RM5.8 billion. Malaysian furniture was exported to more than 160 countries. Apart from the traditional markets, comprising the USA, Japan, the United Kingdom (UK) and Australia, exports of Malaysian furniture had diversified into non-traditional markets, such as South America, West Asia, Africa, Russia and the Association of Southeast Asian Nations (ASEAN). The furniture industry in Malaysia is dominated by small and medium firms, labor-intensive and employing low level automations. The feature of this industry is normally linked to low efficiency. This paper attempts to examine the efficiency of the wooden furniture industry, namely the technical efficiency.

The efficiency term describes the maximum outputs attainable from utilizing the available inputs. A production is efficient if it cannot improve any of its inputs or outputs without worsening some of its other inputs or outputs. Efficiency can be increased by minimizing inputs while holding output constant or by maximizing output while holding inputs constant or a combination of both may increase efficiency.

Several empirical studies using frontier function methodologies have been undertaken with the purpose of measuring firm efficiency but with different results. These differences may have been the results of numerous reasons, including the time period analysed, the degree of sample homogeneity, output aggregation and the method employed (Neff et aI., 1991). For example, Bravo-Ureta and Rieger (1990) examine New England and New York farm efficiency using four production frontier methods. The results of their analysis show that, while large differences exist between estimated average firm efficiency ratios, all four sets of efficiency ratios are correlated within two time periods.

Farrell's works directly measure the technical efficiency with linear programming techniques that simultaneously estimate the production frontier. To estimate the deterministic frontier production function by Farrell (1957), which provides the upper bound of output levels at all combination of inputs, was followed by the works of Aigner and Chu (1968), Timmer (1970), Arfiat (1972). Richmond (1974) and Schmidt (1976) first use mathematical programming techniques, both parametric and non-parametric, and then the econometric approach to measure technical efficiency. Measuring technical efficiency of firms by estimating frontier models is the latest econometric method developed. 
The stochastic frontier production function (SFPF) was independently proposed by Aigner et al. (1977). This differs from the traditional (average) production function in that its residuals have two components: one to account for technical inefficiency and the other to permit random events that affect production. Many authors have altered and generalized the original specification of the SFPF. Forsund et al. (1980), Schmidt (1986), Bauer (1990) and Battese (1992) provide excellent surveys of the literature on frontier analysis.

In this paper, we used the stochastic frontier production function proposed by Battese and Coeli (1992), which followed the models developed by Aigner et al. (1977), and Meeusem and van den Broeck (1977). The advantage of using the stochastic production frontier model is to introduce a disturbance term representing noise, measurement error, and exogenous shock beyond the control of production unit in addition to the efficiency component. The maximum likelihood estimation procedure was employed to obtain parameter estimates. In this study, a Cobb-Douglas stochastic frontier production function is estimated using data from 511 furniture manufacturing industries in Malaysia for the year 2005.

\section{Literature Review}

The parametric approach of benchmarking also includes the stochastic frontier approach (SFA). SFA differs from simple regression analysis in many aspects. For example, whereas simple regression uses ordinary least squares to find the best fit of the average cost function, SFA uses mainly what is called "maximum likelihood" estimation techniques to estimate the frontier function in a given sample.

In addition, SFA separates error components from inefficiency components. In particular, it requires separate assumptions to be made to the distributions of the "inefficiency" and "error" components, potentially leading to more accurate measures of relative efficiency. SFA uses available data in order to estimate the cost function of a relatively efficient firm - known as the "frontier". This function is assumed to be common for all firms and is used to obtain measures of inefficiency.

SFA has the advantage - compared to non-parametric techniques, such as DEA - that it can provide some statistical inference to the functional form of the frontier and the significance of individual explanatory factors upon the shape of the frontier. In addition, since the method uses maximum likelihood estimation, there is no guarantee that the final estimators will hold any desirable statistical properties (unbiasedness, efficiency, consistency) in small samples. Unfortunately, it is difficult to define a clear-cut sample size which inferences become problematic as this will ultimately depend on the quality and nature of the data, the number of explanatory variables and the estimation procedure being followed.

There are vast notable analytical studies of technical efficiency using SFA in manufacturing firm across countries. There are various factors that contribute to technical inefficiency e.g., socio-economic, demographic and regional responsible for technical efficiencies to be different across provinces. In Heru and Subhash (2004) study, the factors considered are: inflation, mean years of schooling, regional location, and sectoral differences. In twenty out of twenty-six provinces the TFP growth was driven by efficiency changes while in four provinces the TFP growth was driven by technological progress.

Most empirical studies concentrate on technical inefficiency since technical inefficiency happens to be an important source of underperformance. Technical inefficiency also embodies all the managerial and organizational sources of inefficiency, what Leibenstein (1966) refers as X-inefficiency. The allocative efficiency of an organization is a comparative measure of how well its prices are according to its marginal productivity. As a conclusion, allocative efficiency relates to prices while technical efficiencies relates to quantities. When comparing between allocative and technical efficiency, it determines the degree of total economic efficiency. Thus when a firm uses its technical resources completely and efficiently, then it can be said to have achieved total economic efficiency. Similarly, when either allocative or technical inefficiency is present, the organization will be operating at less than total economic efficiency; Worthington (2004).

Nik Hashim and Basri (2004) measured (TFP) growth of Malaysian manufacturing sector using stochastic frontier approach with translog production function. They found that between 1990 and 2000 TFP growth was very low for some industries at below unity or even negative for E\&E, transport and food industries. The positive growth is achieved in chemical, textiles, rubber, petroleum and wood. However, this study found that technical efficiency was a major contribution of Total Factor Productivity (TFP) growth.

Study by Yanrui (2000), using the stochastic frontier approach showed that TFP growth was positive for all countries. This study includes seven APEC developed countries and nine APEC developing countries and found that APEC developed countries performed better in terms of TFP growth contribution. Mahadevan (2001) however, studied TFP growth using the Malaysian Manufacturing Survey data of 1981-1996. She divided the data into three periods namely 1981-1984, 1987-1990 and 1991-1996. She found that the contribution of input 
has increased overtime but the contribution of TFP growth was negative in the last two periods due to different reasons. During the second period, the negative contribution of TFP growth was due to a negative contribution of technical progress, whereas during the third period it was due to a negative change in technical efficiency.

Sharma, et al. (2003) estimated technical efficiency and total factor productivity growth in fifty U.S. states from 1977 to 2000 and found that, on average, technical efficiency is around $75 \%$. Other studies on regional technical efficiencies that use different methods include Osiewalski, et al. (2000) and Maudos et al. (2000). Osiewalski et al. (2000) examined productivity disparity between Poland and other Western economies using a Bayesian stochastic frontier. They claimed that at the beginning of Poland's reform its economy exhibited low technical efficiency. Maudos et al. (2000) employed Data Envelopment Analysis to estimate efficiency in Spanish regions using panel data from 1964 to 1993 and they observed that efficiency varies across sectors and time.

\section{Methodology}

A stochastic frontier production function as proposed by Battese and Coelli (1992) is defined as:-

$$
Y_{i}=f\left(X_{i}, \beta\right) \varepsilon^{\varepsilon_{i}}
$$

$Y i$, is the output vector for the $i^{\text {th }}$ firm, $X_{i}$ is a vector of inputs, $\beta$ is a vector of parameter and $\varepsilon_{i}$ is an error term. In this model, a production frontier defines output as a function of a given set of inputs, together with technical inefficiency effects. Furthermore, this model specifies that these inefficiency effects are modelled by other observable explanatory variables and all parameters are estimated simultaneously. The stochastic element of this model allows some observations to lie above the production function, which makes the model less vulnerable to the influence of outliers than with deterministic frontier models.

The stochastic frontier is also called composed error model, because it postulates the error term $\varepsilon_{\mathrm{i}}$ as two independent error components:

$$
\varepsilon_{\mathrm{I}}=\mathrm{v}_{\mathrm{i}}+\mathrm{u}_{\mathrm{i}}
$$

When a symmetric component is normally distributed, $v_{i} \sim\left(N, \sigma_{v}^{2}\right)$, represents any stochastic factors that is beyond the firms' control affecting the ability to produce on the frontier such as luck or weather. It can also account for measurement error in $\mathrm{Y}$ or minor omitted variables. The asymmetric component, in this case distributed as a half-normal, $\mathrm{u}_{\mathrm{i}} \sim\left(\mathrm{N}, \sigma_{\mathrm{u}}^{2}\right), \mathrm{u}_{\mathrm{i}}>0$, can be interpreted as pure technical inefficiency. This component has also been interpreted as an unobservable or latent variable; usually representing managerial ability.

The parameters of $\mathrm{v}$ and $\mathrm{u}$ can be estimated by maximizing the following log-likelihood function:

$$
\ln \left(Y \sim \beta, \lambda, \sigma^{2}\right)=\frac{N}{2} \ln \left[\frac{2}{\pi}\right]-N \ln \sigma+\sum_{i=1}^{N} \ln \left[1-F\left(\varepsilon_{i} \lambda \sigma^{-1}\right)\right]+\frac{1}{2 \sigma^{2}} \sum_{i=1}^{N} \varepsilon_{i}^{2}
$$

Where,

$$
\begin{aligned}
& \varepsilon_{i}=Y_{i}-f\left(X_{i}, \beta\right) \\
& \sigma^{2}=\sigma_{u}^{2}+\sigma_{v}^{2} \\
& \lambda=\sigma_{u} / \sigma_{v} \\
& F=\text { the standard normal distribution function } \\
& N=\text { number of observation }
\end{aligned}
$$

Given the assumptions on the distribution of $\mathrm{v}$ and $\mathrm{u}$, Jondrow et al. (982) showed that the conditional mean of $\mathrm{u}$ given $\varepsilon$ is equal to

$$
E\left(u_{i} \mid \varepsilon_{i}\right)=\frac{\sigma_{u} \sigma_{v}}{\sigma}\left[\frac{f\left(\varepsilon_{i} \lambda \sigma\right)}{1-f\left(\varepsilon_{i} \lambda \sigma\right)}-\frac{\varepsilon_{i} \lambda}{\sigma}\right]
$$

where $f$ and $F$ are the standard normal density and distribution functions evaluated at $\varepsilon_{\mathrm{i}} \lambda / \sigma$. Measures of technical efficiency (TE) for each firm can be calculated

$$
\mathrm{TE}_{\mathrm{i}}=\exp \left(-\mathrm{E}\left[\mathrm{u}_{\mathrm{i}} \mid \varepsilon\right]\right) \text { so that } 0 \leq \mathrm{TE} \leq 1
$$

The Cobb-Douglas stochastic frontier production function in logarithm form is as follows:

$$
\ln \mathrm{VA}_{\mathrm{i}}=\ln \beta_{0}+\beta_{1} \ln \mathrm{C}+\beta_{2} \ln \mathrm{L}_{\mathrm{i}}+\beta_{3} \ln \mathrm{E}_{\mathrm{i}}+\varepsilon_{\mathrm{I}}
$$

where VA represents value added (RM) per year. Independent variables are C (capital, RM), L (number of labour), and $\mathrm{E}$ (energy expenditure). Parameters $\beta_{0}$ denotes the technical efficiency level and $\beta_{\mathrm{i}}$ is elasticities of the various inputs with respects to output level. A summary of data used is presented in Table 1. 


\section{Results and Discussion}

The empirical shown of the stochastic production frontier for the furniture manufacturing industries are presented in Table 2. For comparison purposes both the 'average' production function estimated using ordinary least square (OLS) and the frontier likelihood function are presented. All the coefficients have the expected positive signs implying that an increase in an input ultimately increases the output level. All variables in the stochastic frontier production functions are significantly different from zero at five and one per cent level. Summation of the elasticities of production indicates return to scale of 1.16 respectively for the' average' production function and the stochastic frontier function. The value of return to scale greater than unity suggests that increasing return to scale is prevails. A one-percent increase in all inputs resulted in an increase of 1.16 per cent in output level for the stochastic frontier.

A direct comparison of the parameter estimated for the 'average' production function and stochastic function shows close similarity between the intercepts and inputs coefficients. As can be seen in Table 2, the intercept differences between the two production functions suggest the stochastic frontier functions represent neutral shifts from the 'average' production function. On the other hand, the slope coefficients which display slight differences between the two functions might be due to the inefficient estimates of OLS. Furthermore, by the specification of the likelihood function, the difference between the production function estimated by the OLS and frontier function can be statistically shown by the significance of $\lambda$, implying that there is a significant difference between the two production function.

The significance of the parameter $\lambda$ is able to show that there is sufficient evidence to suggest that technical inefficiency is present in the data. As shown in Table 2, the estimates of the error variances $\sigma_{u}^{2}$ and $\sigma_{v}^{2}$; are 0.0885 and 0.0230 respectively. Therefore, it can be easily seen the variance of one-side error, cr,; is larger than the variance of random error, cr,. Thus the value of $\lambda$ (i.e. $\lambda=\sigma_{v} / \sigma_{u}$ ) of more than one. This clearly shows the dominant share of the estimated variance of one-sided error term, $\boldsymbol{u}$, over the estimated variance of the whole error term. This implies that a great part of the residual variation in output is associated with the variation in technical inefficiency rather than with 'measurement error' which is associated with uncontrollable factors related to the production process.

Following the Battese and Cora (1977), we can also estimate the total variation in output from the frontier that is attributable to technical efficiency using the parameter $\Omega$, where $\Omega$ equal $\sigma_{u}^{2} / \sigma^{2}$. Using this formula, it can be calculated that $\mathrm{W}$ is 0.9789 . This means that about 98 per cent of the discrepancies between observed output and the frontier output are due to technical inefficiency. In other words, the shortfall of observed output from the frontier output is primarily due to factors which are within the control of the firms.

In Table 3, we presented the technical efficiency index using Jondorow et al (1982) procedure. The level of technical efficiency for each individual firm, $e^{-u_{i}}$, is calculated by estimating the one-sided error component $u_{j}$ from equation (4). The minimum estimated efficiency is 1.63 per cent while the maximum is 98.76 per cent, and the mean level of technical efficiency is 34.53 per cent. According to Grabowski et at. (1990), a firm is considered technically inefficient even if the firm registered a technical efficiency index of 82 per cent. By this standard, therefore, the number of firms considered efficient technically is only 8.4 per cent of the total firms in the sample under study. Separating the composed error term of stochastic frontier model to estimate the level of technical inefficiency for a sample of furniture manufacturing industries in Malaysia, the analysis shows that, on average, there is 54.47 per cent technical inefficiency in the sample. This means that firm output is 54.47 per cent less than the maximal output which can be achieved from the existing level of inputs.

\section{Conclusion and Policy Implications}

The study has shown the furniture industry in Malaysia, despite being able to increase its production significantly over the years, produce at a low level of efficiency. This has resulted in an inefficient utilization of resources and so does the potential to increase firm output from the existing level of inputs. Through the effective use of existing inputs the firm value-added can be increased by almost 55 per cent at the aggregate level without any additional cost to the firms. In terms of value it can be translated to about RM2.4 billion loss due to inefficiency.

The study also revealed the technical inefficiency on individual firms varies, from 1.63 to 94.69 per cent. This is due to the structure of the industry being characterized as unorganized with a few large firms at one end and many small firms scattered at the other. Policy should be driven to consolidate the industry to reap the economies of scale used which will lead to more efficiency.

Finally, steps must be taken to increase the usage of technology in this industry, in order to improve the efficiency. Concurrently, the focus will be the quality of human resources and the policy accompanying it. Attempts to maximize production through improve in efficiency will not be achieved without the appropriate 
skills of human resources.

\section{References}

Afriat, S.N. (1972). Efficiency Estimation of Production Functions. International Economic Review, Vol. 13, pp. 568-598.

Aigner, D.J. and Chu, S.F., (1968). On Estimating the Industry Production Function. American Economic Review, Vol. 58, pp. 826-839.

Aigner, D.J.l., Lovell, C.A.K. and Schmidt, P. (1977). Formulation and Estimation of Stochastic Frontier Production Function Models. Journal 0/ Econometrics, Vol. 6, pp. 21-37.

Battese, G .E. (1992). Frontier Production Functions and the Technical Efficiency: A Survey of Empirical Applications in Agricultural Economics. Agricultural Economics, Vol. 7, pp. 185-208.

Battese, G. E. and T. J. Coelli. (1992). Frontier Production Function, technical efficiency and panel data: with application to Paddy Farmers in India. Journal of Productivity Analysis, Vol. 3, pp. 153-169.

Bauer, P.W. (1970). Recent Development in Econometric Estimation of Frontier. Journal o/Econometrics. Vol. 46, pp. 3956.

Bravo-Ureta, B.E. and Rieger, L. (1990). Alternative Production Frontier Methodologies and Dairy Farm Efficiencies. Journal Agricultural Economics, Vol. 41, pp. 215-226.

Farrell, M.l. (1957). The Measurement of Productive Efficiency. Journal of Royal Statistic Society Series. A, Vol. 120, pp. 253-290.

Forsund, P.R., Lovell, C.A.K. and Schmidt, P. (1980). A Survey of Frontier Production Functions and of their Relationship to Efficiency Measurement. Journal Econometrics, Vol. 13, pp. 5-25.

Grabowski, R. et al. (1990). A Ray-Homothetic and Efficiency: Grain Farms in Southern Illinois. European Review of Agricultural Economics, Vol. 17, pp. 435-448.

Heru M. and Subhash C. S. (2004). Technical Efficiency and Productivity Analysis in Indonesian Provincial Economies December 2004. Department of Economics, Southern Illinois University Carbondale.

Jondrow, 1, Lovell, C.A.K., Materov, I.S. and Schmidt, P. (1982). On the Estimation of Technical Inefficiency in. the Stochastic Frontier Production Function Model. Journal Econometrics, Vol. 19, pp. 233-238.

Leibenstein, Harvey (1966). Allocative Efficiency vs. X-Efficiency. American Economic Review, Vol. 56 (3), pp. $392-415$.

Maudos, J., Pastor J.M and L. S. (2000). Efficiency And Productive Specialization: An Application To The Spanish Regions, Regional Studies, Vol. 34, pp. 829-834.

Mahadevan, R. (2001). Assessing the Output and Productivity Growth of Malaysia's Manufacturing Sector. Journal of Asian Economics, Vol. 12(4), pp. 587-597.

Meeusen, W. and Van den Broeck, 1, (1977). Efficiency Estimation from Cobb-Douglas Production Functions with Composed Error. International Economics Review, Vol. 18, 435-444.

Neff, D.L., Garcia, P. and Honbaker, R.H. (1991). Efficiency Measure Using the Ray-Homothetic Function: A Multi Period Analysis. Journal of Agricultural Economics, Vol. 23, pp. 113-121.

Nik Hashim Nik Mustapha and Basri Mohd Talib (2004). Technical Efficiency and Total Factor Growth in Selected Malaysian Manufacturing Industries. In Doris Padmini, Poo Bee Tin \& Mohd Nasir Mohd Saukani (ed), proceeding Seminar Economic and Social Competitiveness Towards Strengthening Economic development, 11-13 June, 2004, Port Dickson Malaysia.

Osiewalski, J., G. K. and Steel M. F. J. (2000). Stochastic Frontier Analysis of Output Level And Growth In Poland And Western Economics, Economics of Planning, Vol. 33(3), pp. 185-202.

Richmond, 1. (1974). Estimating the Efficiency of Production. International Economics Review, Vol. 15, pp. 515-521.

Schmidt, P. (1976). On the Statistical Estimation of Parametric Frontier Production Functions. Review Econometric and Statistic, Vol. 58, pp. 139-150

Schmidt, P. (1986). Frontier Production Function. Econometric Review, Vol. 4. pp. 289-328.

Sharma, S.C., K. Sylwester and H. M. (2003). Technical Efficiency and Total Factor Productivity Analysis Across U.S. States: 1977-2000, Manuscript, Department of Economics, Southern Illinois University Carbondale, Illinois

Timmer, C.P. (1970). On Measuring Technical Efficiency. Food Research Institute Studies, Vol. 9, pp. 99-171. Worthington, A. C. (2004). Frontier Efficiency Measurement in Health Care: A Review of Empirical Techniques And Selected Applications. Medical Care Research and Review, Vol. 61 (2), pp. 135-170. 
Yanrui Wu. (2000). Openness, Productivity and Growth In The Asian-Pacific Economics: An Alternative Approach. Paper presented at the 7th Convention of the East Asian Economic Association, 17-18 November, Singapore.

Table 1. Summary of Data Used

\begin{tabular}{lrrrr}
\hline & Minimum & \multicolumn{1}{c}{ Maximum } & Mean & Std. Deviation \\
\hline Output (RM'000) & 7.66 & 246128.62 & 12330.80 & 27458.54 \\
Raw material (RM'000) & 6.52 & 188883.20 & 7623.14 & 18246.71 \\
Value added (RM'000) & 1.14 & 81938.15 & 4707.65 & 9810.71 \\
Capital (RM'000) & 1.18 & 129759.40 & 4540.61 & 12000.51 \\
Energy expenditure (RM'000) & 0.26 & 3114.17 & 215.12 & 431.72 \\
Numbers of labour & 2.00 & 1424.00 & 116.36 & 182.18 \\
\hline
\end{tabular}

Table 2. Empirical Estimates of Ordinary Least Square (OLS) and Frontier Production Function

\begin{tabular}{lcc}
\hline Variables & OLS & Frontier \\
\hline Intercept & 7.2210 & 8.0461 \\
& $(0.2357)^{*}$ & $(0.1533)^{*}$ \\
$\ln \mathrm{C}$ & 0.0546 & 0.0591 \\
& $(0.0222) *$ & $(0.0153)^{*}$ \\
$\ln \mathrm{L}$ & 0.8500 & 0.8512 \\
& $(0.0491)^{*}$ & $(0.0268)^{*}$ \\
$\ln \mathrm{E}$ & 0.2488 & 0.2521 \\
& $(0.0354) *$ & $(0.0173)^{*}$ \\
$\mathrm{R}^{2}$ & 0.9019 & \\
$\lambda=\sigma_{\mathrm{v}} / \sigma_{\mathrm{u}}$ & & 6.8172 \\
& & $(0.3832)^{*}$ \\
$\sigma=\sqrt{\sigma_{\mathrm{u}}^{2}+\sigma_{\mathrm{v}}^{2}}$ & & 1.0452 \\
$\sigma_{\mathrm{v}}^{2}$ & & $(0.0312) *$ \\
$\sigma_{\mathrm{u}}^{2}$ & & 0.0230 \\
$\log$-likelihood & & 1.0693 \\
\hline
\end{tabular}

Note: Figure in parentheses is standard error

* Significant at 1 percent level

Table 3. Firm Specific Technical Efficiencies in the Stochastic Production Frontier

\begin{tabular}{lcc}
\hline Percent & Frequency & Percent \\
\hline $0.00-9.99$ & 15 & 2.94 \\
$10.00-19.99$ & 37 & 7.24 \\
$20.00-29.99$ & 69 & 13.50 \\
$30.00-39.99$ & 110 & 21.53 \\
$40.00-49.99$ & 94 & 18.40 \\
$50.00-59.99$ & 72 & 14.09 \\
$60.00-69.99$ & 37 & 7.24 \\
$70.00-79.99$ & 27 & 5.28 \\
$80.00-89.99$ & 33 & 6.46 \\
$90.00-99.99$ & 17 & 3.33 \\
\hline Total & 511 & 100.00 \\
\hline Minimum & & 1.63 \\
Maximum & & 98.76 \\
Mean & & 45.53 \\
Std. Deviation & & 21.35 \\
\hline
\end{tabular}

